\title{
Relating early hydration, specific surface and flow loss of cement pastes
}

\author{
Sara Mantellato (1) - Marta Palacios · Robert J. Flatt
}

Received: 5 December 2018/ Accepted: 14 December 2018/Published online: 4 January 2019

(C) The Author(s) 2019, corrected publication 2019

\begin{abstract}
Flow loss in superplasticized systems has been mainly explained in qualitative and comparative ways over the past years. This is due to the intrinsic complexity of the underlying mechanism involving a change in the agglomeration degree as a result of cement hydration. The lack of robust and reliable experimental methodologies must have additionally discouraged researchers from attempting to understand the phenomena of flow loss in quantitative terms. Thanks to new analytical methods, it was possible to prove that after the so-called onset point, yield stress increases exponentially with the increase of both heat rate measured by isothermal calorimetry and specific surface. This paper also identifies the existence of a direct proportionality between the increase of heat rate and the increase of specific surface area during the
\end{abstract}

Electronic supplementary material The online version of this article (https://doi.org/10.1617/s11527-018-1304-y) contains supplementary material, which is available to authorized users.

S. Mantellato $(\bowtie) \cdot$ M. Palacios · R. J. Flatt Institute for Building Materials, ETH Zürich, StefanoFranscini-Platz 3, 8093 Zurich, Switzerland e-mail: sara.mantellato@ifb.baug.ethz.ch

R. J. Flatt

e-mail: flattr@ethz.ch

M. Palacios

Eduardo Torroja Institute for Construction Science,

Serrano Galvache 4, 28033 Madrid, Spain acceleration period, most likely reflecting the nucleation and growth nature at this stage of the cement hydration.

Keywords Superplasticizers - Yield stress $\cdot$ Heat rate $\cdot$ Isothermal calorimetry $\cdot$ BET model

\section{Introduction}

It is widely known that the loss of fluidity of cement pastes may be affected by a number of factors, such as cement hydration, mixing procedure, as well as type, dosage and addition mode of superplasticizers, specifically, those based on Polycarboxylate Ether polymers (PCEs) [1-7]. The fact that these parameters can act simultaneously makes very challenging to describe flow loss in quantitative terms. For this reason, the responsible mechanism for flow loss in superplasticized cementitious systems is comparatively much less studied in the literature than the effects of PCEs on the initial dispersion. As common practice, PCEs with a lower amount of charges on the backbone (lower initial adsorption) and short side chains are commonly used, if extended workability time is desired [2, 3, 8]. On the other hand, polymers with a higher amount of charges are generally preferred when requirements of workability retention are of lesser interest. However, a deep understanding about the direct impact of PCEs with different molecular structures and their dosages on the evolution of the rheological properties of fresh 
cementitious systems have barely been reported in the literature.

As a consequence of the intrinsic complexity of cementitious systems, the identification of the rheological features might result confused and often mistaken. Therefore, it is fundamental to recall here the notions of thixotropy and irreversible structural build-up. The former is a reversible process by which the structure of a fluid, broken down during shear, is rebuilt at rest due to the flocculation of cement particles through colloidal attractive forces [9-11]. Introduced for the first time in the technical terminology by Tattersall and Banfill [12], the irreversible structural build-up refers to the impossibility for a fluid to fully recover its initial yield stress when exposed to high shear, as for concretes in a mixer. Unfortunately, concretes exhibit both behaviors and the distinction of the two is still matter of discussion. Some advances have been made to understand this mechanism for nonadmixed cementitious systems studying critical deformations at different strains [10, 13]. Strains on the order of $10^{-3}$ correspond to the flocculation between nanoscopic hydrates in the first minutes after the contact of cement with water, likely due to the nucleation of $\mathrm{C}-\mathrm{S}-\mathrm{H}$ bridging particles. Conversely, higher strains are required to break stronger and more rigid bonds at the contact points between the $\mathrm{C}-\mathrm{S}-\mathrm{H}$ particles growing during hydration $[10,14,15]$.

Among other factors, such as $w / c$ ratio or cement composition, the presence of PCEs introduces a further variable in the system, making the abovementioned phenomena even more difficult to discern. In fact, adsorbed PCEs play a key role at the solid/ liquid interface, controlling the state of flocculation that, in turn, has a strong effect on the rheological properties. Their adsorption on cement particles may, however, be compromised due to preferential sequestration by hydrated aluminate phases [16-18] or adsorption on ettringite $[19,20]$. In both cases, the crystal nucleation and growth of the hydrates cause a significant increase in the specific surface area $[19,21,22]$. This leads to a reduction of the amount of polymer available for the dispersion [1, 16, 17, 23], affecting also workability over time, setting behavior and development of the microstructure [19, 24-26].

This paper is part of a more global series of publications based on [27] and aimed at quantitatively answering the question of the flow loss in cement pastes in presence of PCEs having different molecular architecture. An important part of the research endeavor was the development of reliable methodologies, still missing in the literature, to enable the proper quantification of the main factors involved, in particular the specific surface area, the evolution of which is expected to have a profound effect on yield stress.

In the present paper, the methodology to study that evolution is reported. In particular, we establish how the coupling of yield stress and calorimetry measurements can serve to accurately identify the onset of the acceleration period. In such timeframe, an original correlation between the exponential rise of the yield stress to both of heat rate and of specific surface area is also shown, including a dependency on the molecular structure and dosage of PCEs.

\section{Materials and methods}

\subsection{Materials}

Five $25 \mathrm{~kg}$-bags of fresh commercial CEM I 52.5R Ordinary Portland Cement (OPC) (Holcim Group Services Ltd./Holcim Technology Ltd., Zurich, Switzerland) were used in the present work. The characterization in terms of mineralogical composition, particle size distribution and $\mathrm{SSA}_{\mathrm{BET}}$ are reported in Online Resource 1. The content of the cement bags was mixed and transferred into three PE screw cap barrels to limit possible changes in composition due to hydration and carbonation reactions.

Five non-commercial polycarboxylate ether-based comb polymers, provided by SIKA AG, were used as PCEs. The structural parameters are described in Table 1 . They were synthesized by copolymerization. The methacrylic ester and methacrylic acid (MA, Sigma-Aldrich) were simultaneously dosed into the reactor filled with ultrapure water (UPW) for $4 \mathrm{~h}$. In parallel, initiator and chain transfer agent were dosed. Afterwards, they were ultrafiltered (Labscale TFF System, Merck Millipore) to remove residual monomers, side chains, and salts. The molar masses of these polymers were determined by size exclusion chromatography (SEC) with an Agilent 1260 Infinity system (Agilent Technologies, Santa Clara, CA, USA) equipped with refractive index (RI) and Multi-Angle Laser Light Scattering (MALS) detectors. The eluent for $\mathrm{SEC}$ was $\mathrm{Na}_{2} \mathrm{HPO}_{4} 0.067 \mathrm{~mol} / \mathrm{L}$ at a flow rate of $1 \mathrm{~mL} / \mathrm{min}$. The carboxylate-to-ester ratio $(\mathrm{C} / \mathrm{E})$ 
Table 1 Characteristic molecular parameters of the used comb-shaped copolymers

\begin{tabular}{llllllrl}
\hline PCE type & $M_{w}(\mathrm{kDa})$ & C/E ratio & $P$ & $n$ & $S_{\mathrm{PCE}}\left(\mathrm{nm}^{2} / \mathrm{mol}\right)$ & $K \times 10^{5}$ & $\#_{\mathrm{COO}}^{-}(\mathrm{mmol} / \mathrm{g} \mathrm{PCE})$ \\
\hline 2.5PMA1000 & 31.9 & 2.70 & 23 & 24 & 123 & 52 & 2.11 \\
4.0PMA1000 & 25.4 & 4.13 & 23 & 18 & 101 & 126 & 2.87 \\
2.5PMA2000 & 64.0 & 2.75 & 46 & 28 & 262 & 13 & 1.18 \\
4.0PMA2000 & 45.7 & 4.36 & 46 & 19 & 198 & 39 & 1.77 \\
2.5PMA5000 & $106.0^{*}$ & 1.89 & 115 & 20 & 399 & 2 & 0.36 \\
\end{tabular}

$n$ is the number of units or the number of side chains for a single molecule. The molar masses, expressed in kDa, were estimated using the absolute method MALS [28]. The asterisk indicates the $M_{w}$ determined by SEC calibrated with PEO/PEG molar mass standards. $\mathrm{C} / \mathrm{E}$ is the number of monomers in the backbone for a single side chain that contains $P$ monomers of ethylene oxide. $S_{\mathrm{PCE}}$ is the surface occupied by a single adsorbed molecule from [29]. $K$ is the adsorption equilibrium constant from [23]. \#COO ${ }^{-}$is the content of carboxylate groups in mmol per $\mathrm{g}$ of dry polymer

indicates the grafting density of the side chains and was calculated knowing the number of charges quantified by titration [27].

\subsection{Methods}

\subsubsection{Cement paste preparation}

Two kilogram of OPC were sampled from different heights of PE barrel to prepare a cement paste with ultrapure water (UPW) with a constant water to cement ratio $(w / c)$ of 0.3 using a Hobart mixer (N50 5-Quart Mixer). PCEs were dosed directly with the mixing water (direct addition). The mixing procedure was started after pouring the cement in the solution. This consists of $30 \mathrm{~s}$ at low mixing speed (139 rpm), $30 \mathrm{~s}$ at high speed $2(285 \mathrm{rpm}), 30 \mathrm{~s}$ of stop were necessary to scrape the paste off from the bowl surface, then, 4 min at speed 2 for the final mixing.

Just after the mixing, the cement paste was poured in 10 plastic beakers containing each $250 \mathrm{~g}$ of paste, then covered with Parafilm to avoid water evaporation and uptake of carbon dioxide over time. At the chosen time of rest, each small batch of paste was mixed for $3 \mathrm{~min}$ at $800 \mathrm{rpm}$ with a vertical mixer (Eurostar power control visc with a 4-bladed propeller stirrer, IKA) to study the evolution of the cement paste properties, namely fluidity and specific surface area over time.

In absence of PCEs, cement pastes having $w / c$ ratios ranging between 0.494 and 0.55 were prepared to reach a sufficiently large initial spread diameter for a reliable evaluation of yield stress. The initial procedure as well as the partition of the paste are the same as presented above. However, it is known and further confirmed in Fig. 1 that a change of the initial $w / c$ ratio can strongly affect the dissolution/precipitation processes. Therefore, the additional water was added $10 \mathrm{~min}$ after the first contact with water to pastes having initial $w / c$ ratio of 0.3 and mixed at $800 \mathrm{rpm}$ for 2 min. Calorimetric tests were started just after the end of the mixing. Using this procedure, we could demonstrate that a delayed addition of water, keeping the same $w / c$ ratio at the beginning of the hydration and, consequently, the same supersaturation of the pore solution, does not affect significantly the

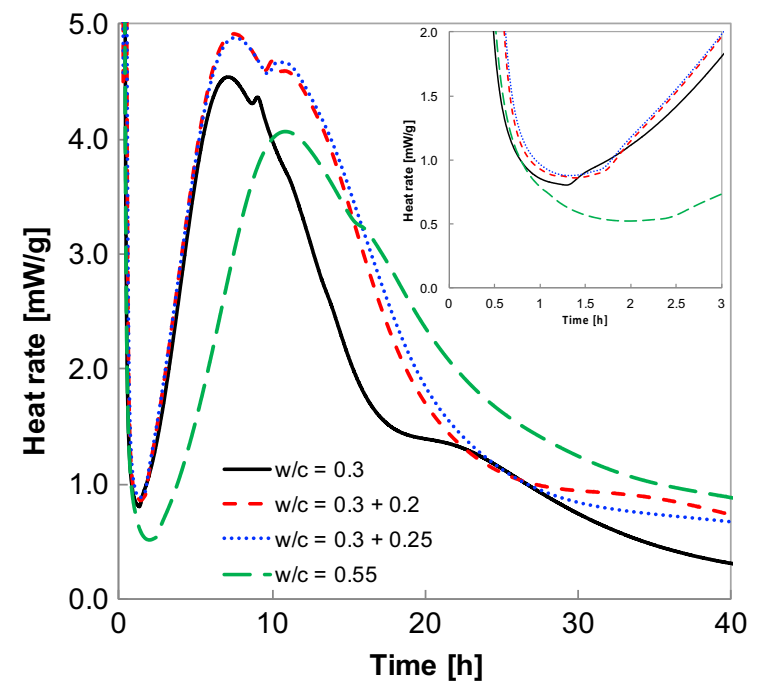

Fig. 1 Calorimetric curve shown as heat rate over time for cement pastes without PCE at different delayed addition of water starting from the same initial $w / c$ of 0.3 . A sample at $w / c$ of 0.55 was included for comparison. The zoomed area shows the heat rate evolution over the first $3 \mathrm{~h}$ of hydration 
dissolution process in the first hours of hydration, as shown in the zoomed area of Fig. 1 by similar initial parts of the calorimetric curves. However, main differences are noticed in the intensity of the silicate peak at later times.

\subsubsection{Spread flow tests}

After a predetermined resting time, each cement paste sample was remixed for $3 \mathrm{~min}$ at $800 \mathrm{rpm}$ with a vertical mixer (Eurostar power control visc with a 4-bladed propeller stirrer, IKA) before the spread flow test. This breaks down the bonds formed by thixotropic build-up while the cement is left at rest and puts samples in a comparable shear history state before being measured. The spread flow test was performed by using a plastic cylindrical mould, having both diameter and height of $5 \mathrm{~cm}$. It was placed on a flat horizontal glass plate with a smooth surface previously humidified with a sponge. The mold was filled with the cement paste 1 min after mixing. The cylinder was slowly lifted 1 min later to let the paste flow. Two perpendicular diameters of the spread at the base of the sample were then measured. The glass plate and the cylinder with the remaining paste were weighed to calculate the density of the cement paste.

\subsubsection{Isothermal calorimetry}

Calorimetric measurements were performed on about $5 \mathrm{~g}$ of paste in an isothermal calorimeter TAM Air (Waters GmbH, UB TA Instruments, Eschborn, Germany) at $23{ }^{\circ} \mathrm{C}$. The calorimetric test was started just after the mixing and performing the spread flow at $10 \mathrm{~min}$. The exact starting time of the measurement was considered to guarantee the right calculation of both heat rate, expressed in $\mathrm{mW} / \mathrm{g}_{\mathrm{dry}}$ cement, and cumulative heat, expressed in $\mathrm{J} / \mathrm{g}_{\text {dry cement }}$, at the time corresponding to the spread flow tests. Owing to both instrumental and operative limitations, calorimetric data can only be considered reliable 30-40 min after the start of the experiment [30]. This time is indeed necessary to let the sample reach the set temperature. By doing this, information relating to the aluminate dissolution (that makes its most significant contribution to cumulative heat in the first minutes of hydration) is partially omitted.

\subsubsection{Stopping of cement hydration}

Solvent exchange was adopted to efficiently stop cement hydration by the removal of the capillary water. In this work, hydration had to be stopped on numerous samples of cement pastes over the workability timeframe, that might last from one to several hours, depending on both polymer dosage and structure. The solvent exchange procedure, validated for anhydrous cementitious phases and synthetic ettringite $[31,32]$, implies the mixing of cold isopropanol (IPA, Sigma-Aldrich, puriss. p.a., ACS reagent $>99.8 \%$ ) at $5{ }^{\circ} \mathrm{C}$ with the cement paste at the ratio cement paste/solvent ratio of 10 . The drying step was applied on about 7-8 $g$ of fresh cement paste.

The procedure proposed here for early hydrated cement pastes involves two steps of filtration: in the first step, fresh pastes are poured in the barrel $\left(V_{\max }=200 \mathrm{~mL}\right)$ of a stainless-steel pressure filter holder previously mounted with a nylon $0.45 \mu \mathrm{m}$ membrane filter (Sartorius Stedim Biotech) under air pressure (4 bar) to remove most of the superplasticized interstitial liquid. Afterwards, the moist paste is taken from the filter and put in contact with the solvent and mixed in a beaker for $1 \mathrm{~min}$, keeping the solvent/ powder ratio of 10 . The suspension is poured and filtered into the barrel of stainless-steel pressure filter under air pressure to filter the excess of solvent out. The moist powder on the filter is, finally, stored in a desiccator with a calcium chloride saturated solution (32\% RH at $20{ }^{\circ} \mathrm{C}$ ) until constant mass. Dried powders were, then, gently homogenized in an agate mortar before $\mathrm{SSA}_{\mathrm{BET}}$ measurements.

\subsubsection{SSA $A_{B E T}$ measurements}

The BET surface area measurements $\left(\mathrm{SSA}_{\mathrm{BET}}\right)$ were carried out on samples which hydration process was previously stopped. A BET multi-point nitrogen physisorption apparatus (Micromeritics Tristar II 3020) was used. The nitrogen adsorption was measured from an 11-points isotherm at a relative pressure $P / P_{0}$ range of $0.05-0.30$ at $77 \mathrm{~K}$. The SSA determinations were repeated three times for each sample. The samples were degassed in an external degassing station (VacPrep 061 from Micromeritics) at $40{ }^{\circ} \mathrm{C}$ under $\mathrm{N}_{2}$ flow (with a maximum flux of about $3 \times 10^{-3} \mathrm{~m}^{3} / \mathrm{h}$ ) for $16 \mathrm{~h}$. Under these conditions, 
the microstructure of early hydration products as well as gypsum still present in the fresh cement pastes is not affected [31, 32].

\subsection{Yield stress from spread flow measurements}

The shape of cementitious materials at stoppage is well accepted to be related to the yield stress [33-36]. Over the past years, a greater attention has been taken to quantitatively obtain reliable relations between yield stress values and either spread flow or slump tests. Roussel and Coussot [37] demonstrated that high yield stresses lead to deformation involving extensional flow. For very low spreads, they express yield stress by the following equation:

$\tau_{0}=\frac{\rho V g}{\sqrt{3} \pi R^{2}}$

where $\rho$ and $V$ are the density and the volume of the sample, respectively, $R$ is the radius of the spread and $g$ the standard gravity. As expressed elsewhere [38], the spread flow depends on the sample volume and the mould geometry in addition to the yield stress, which is a material property.

Roussel et al. [39] demonstrated that samples with low yield stress are subject to pure shear flow at very large diameters. The proposed model relates the characteristics of the cement paste, namely either height or radius, to the variation of the pressure in the sample. The yield stress is then calculated as:

$\tau_{0}=\frac{225}{128 \pi^{2}} g V^{2} R^{-5}-\lambda \frac{R^{2}}{V}$

where surface tension effect is considered through the last term for which the coefficient $\lambda$ of 0.005 is proposed as a reasonable value for most cases.

Flatt et al. [38] proposed to combine both expressions above, Eqs. 1 and 2, using an exponential function of the spread diameter:

$\tau_{0}=\exp (b-a \cdot D)$

where $D$ is the spread diameter, $a$ and $b$ are fitting parameters corresponding to 0.3506 and 8.1505, respectively. In the context of this work, the fitting parameters $a$ and $b$ were slightly changed to 0.3480 and 7.9473, respectively, considering that the averaged density of the produced cement pastes is $2.00 \mathrm{~g} / \mathrm{cm}^{3}$ and the used cylindrical mould. In the following plots, the updated version of this model is referred to as "Flatt et al. [38]—adapted".

Some years later, the two analytical solutions represented by Eqs. 1 and 2 were merged in a different way, obtaining an empirical solution that covers the limits of both high and low deformations [40]. An advantage over the previous interpolation is that the volume and the sample density dependence are explicitly included:

$\tau_{0}=\frac{225 \rho g V^{2}}{\left[128 \pi^{2} R^{5}\left(1+\frac{225}{128 \pi} \cdot \sqrt{3} V R^{-3}\right)\right]}-\lambda \frac{R^{2}}{V}$

More recently, Pierre et al. [41] intended to rationalize the previous equations and to develop an ex novo model valid for intermediate flow regimes. Their objective was to account for the shape of the sample at the stoppage. Because of this, they consider that the upper part of the sample keeps the shape of the original mould, while the spreading sample around the central part is considered almost unsheared. Equation 5 enables the reliable quantification of the yield stress regardless of the flow regime, sample volume or mould shape. However, the calculation of the yield stress is quite elaborate and is only presented for cylindrical moulds. This leads to the following solution:

$\tau_{0}=\left(\frac{-b-\sqrt{b^{2}-4 a c}}{2 a}\right)^{2}$

$$
\begin{aligned}
a= & \frac{\pi R_{0}^{2} \sqrt{3}}{\rho g}, \\
b= & {\left[\frac{8 \pi}{15}\left(R-R_{0}\right)^{\frac{5}{2}}+\frac{4 \pi}{3} R_{0}\left(R-R_{0}\right)^{\frac{3}{2}}+\pi R_{0}^{2}\left(R-R_{0}\right)^{\frac{1}{2}}\right] . } \\
& \sqrt{\frac{2}{\rho g}} \text { and } c=-V
\end{aligned}
$$

where $V$ is the volume of the sample, $R$ and $R_{0}$ are the radius of the spread and the radius of the cylinder, respectively.

In two independent works, it was demonstrated that the surface tension effect cannot be neglected for high spread values corresponding to about $1-2 \mathrm{~Pa}[38,39]$. The model proposed by Pierre et al. [41] does not include the contribution of the surface tension effect. 
However, it can be easily included in the same way as Roussel et al. did [39]. The resulting equation as "Pierre et al. [41]—adapted" is:

$\tau_{0}=\left(\frac{-b-\sqrt{b^{2}-4 a c}}{2 a}\right)^{2}-\lambda \frac{R^{2}}{V}$

This upgraded version of the equation proposed by Pierre et al. is considered as the benchmark model because it holds throughout the range of spread values and does not involve any fitting parameters.

A closer look at the relative value of the different models with respect to the benchmark is given in Fig. 2.

This figure shows major deviations for those models that can be reliably applied only for either very low or very high diameters, respectively. The empirical equation proposed by Zimmermann et al. [40] suffers at the intermediate range of spread values, reaching a relative difference higher than $25 \%$. In contrast, the simple interpolation using an exponential function (Flatt et al. [38]-adapted) offers a very good match to the benchmark over the whole range of spreads. For this reason and because of the simplicity of its mathematical expression, this relation has been used to analyze flow spread tests through this paper.

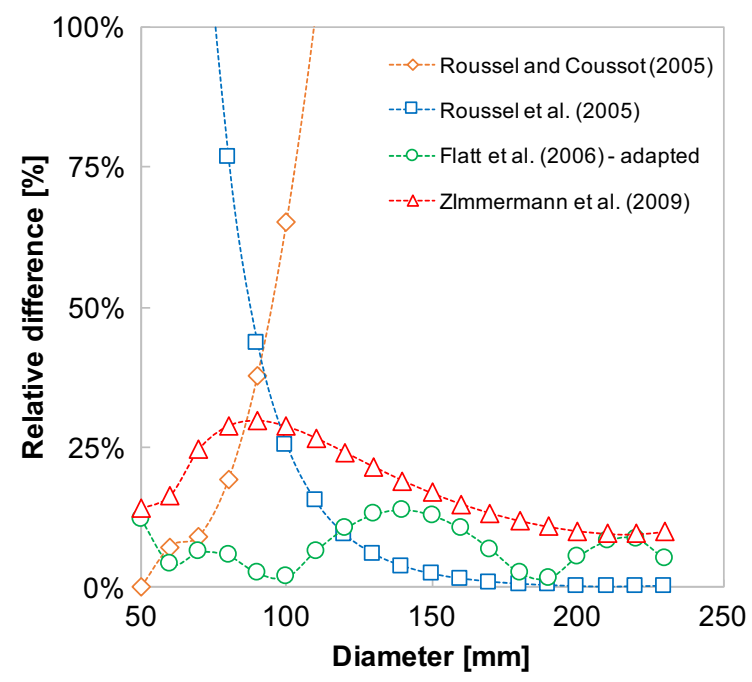

Fig. 2 Comparison between different models for the calculation of the yield stress and the adapted model proposed by Pierre et al. [41], expressed as relative error in percentage, by varying the spread diameter. The sample density is $2.00 \mathrm{~g} / \mathrm{cm}^{3}$ and the cylinder has a volume of $98 \mathrm{~cm}^{3}$

\section{Experimental results}

\subsection{Yield stress evolution}

Figure 3 shows the evolution of the fluidity in relation to the dosage for the polymer 2.5PMA1000. Similar trends with the other 4 polymers are reported in Online Resource 2. Different concentrations were selected to cover a broad range of spread diameters for each polymer at the beginning of hydration.

The initial fluidity, expressed as yield stress $(\mathrm{Pa})$ and calculated by the Eq. 3, depends on the polymer dosage and structure. Specifically, the yield stress increases when the dosage decreases. Generally, it is noticed that all polymers lead to a yield stress that rapidly stabilizes and then evolves only very slowly during a period that we define as open time. This is followed by a rapid increase of yield stress, which we have tried to correlate to polymer structure and dosage. It should be noted that the first data points after the mixing, represented as empty symbols, are collected before the start of the isothermal calorimetry measurements. Therefore, they cannot be related to the first steps of hydration kinetics and are not included in our subsequent data analysis.

Refludification, evidenced as an increase of the spread diameter some minutes after mixing, is most

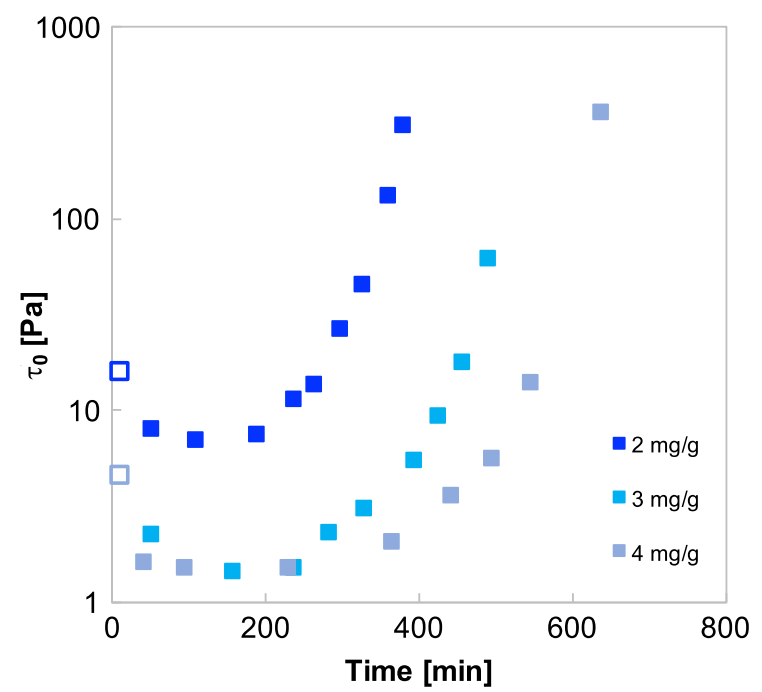

Fig. 3 Evolution of yield stress over time in presence of the polymer 2.5PMA1000, showing data series for different dosages in $\mathrm{mg}$ of polymer/g cement. The empty symbols indicate the first data that cannot be related to isothermal calorimetry measurements 
clearly observed with the polymers having a $\mathrm{C} / \mathrm{E}$ ratio of 2.5. However, this effect is less evident or even absent with polymers with higher $\mathrm{C} / \mathrm{E}$ ratio. Such effects depend on the sulfate content of cement and the molecular structure of the polymer [42]. In essence, it relates to a possible sulfate competition $[40,43]$. Therefore, polymers having high sensitivity to sulfates should be most susceptible to refluidication [40, 44]. Refludification is also an example of how mixing affects properties. Other examples include the so-called "irreversible structural breakdown" [12]. In the context of this work, it was noticed that a too short mixing time would lead to an underestimation of the polymer dispersion ability. As a consequence, the polymer could be overdosed, causing some pastes to segregate even after few hours. For this reason, the impact of mixing duration was carefully studied and it was found that a mixing time between 4 and 6 min could limit such problems.

The developed protocol involved the preparation of large quantities of cement pastes by using the Hobart mixer. Since this is a rotation rate-controlled mixer we could only set the mixing speed and time, so that the mixing energy have changed from case to case depending on the cohesion of the paste. To the best of our knowledge, there is no alternative approach to overcome this issue when using rotation rate-controlled mixers.

\subsection{Specific Surface Area (SSA)}

The $\mathrm{SSA}_{\mathrm{BET}}$ of the anhydrous cement is around $1 \mathrm{~m}^{2} /$ g. Figure 4 emphasizes that the $\operatorname{SSA}_{\mathrm{BET}}$ changes after the mixing of cement with water and polymer, ranging approximately from 2 to $3.5 \mathrm{~m}^{2} / \mathrm{g}$ in the studied timeframe. The changes in $\mathrm{SSA}_{\mathrm{BET}}$ are lower for the 4PMA1000 polymer with a higher C/E. For the polymer with a lower $\mathrm{C} / \mathrm{E}$, the $\mathrm{SSA}_{\mathrm{BET}}$ increases more (Fig. 4). Also, in all cases, it appears to be a period of slight change followed by one of more substantial increase. As shown in Fig. 5, no significant changes can be observed by varying the $w / c$ ratio in absence of PCE, in agreement with the evolution of the heat (Fig. 1). This confirms that the delayed addition of the water does not modify the hydration of cement in the first hours. The initial mixing stage is however very

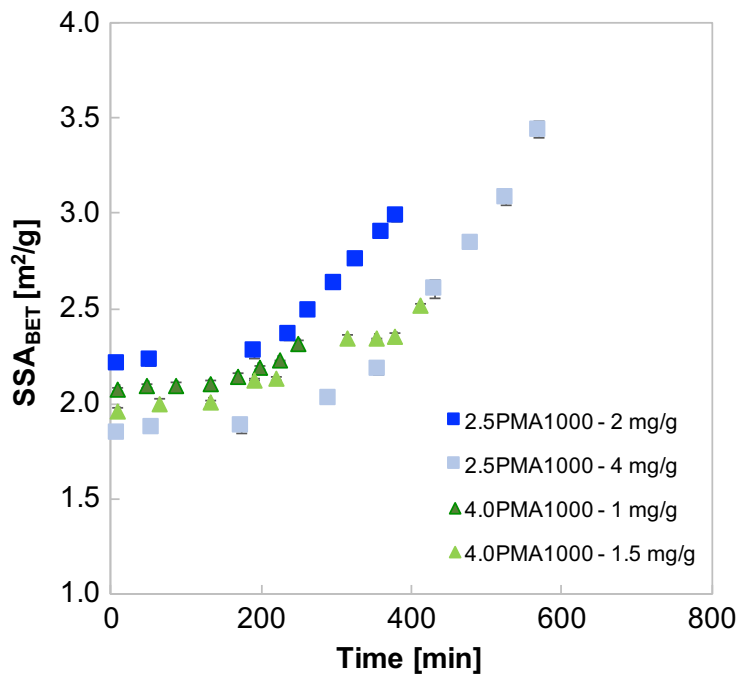

Fig. $4 \mathrm{SSA}_{\mathrm{BET}}$ evolution by varying the polymer dosage for the polymers 2.5PMA1000 and 4.0PMA1000. The results are shown as the mean values and the standard deviation of the mean for $n_{\text {samples }}=3$. The error bars are included, but often not visible because they are smaller than the data markers

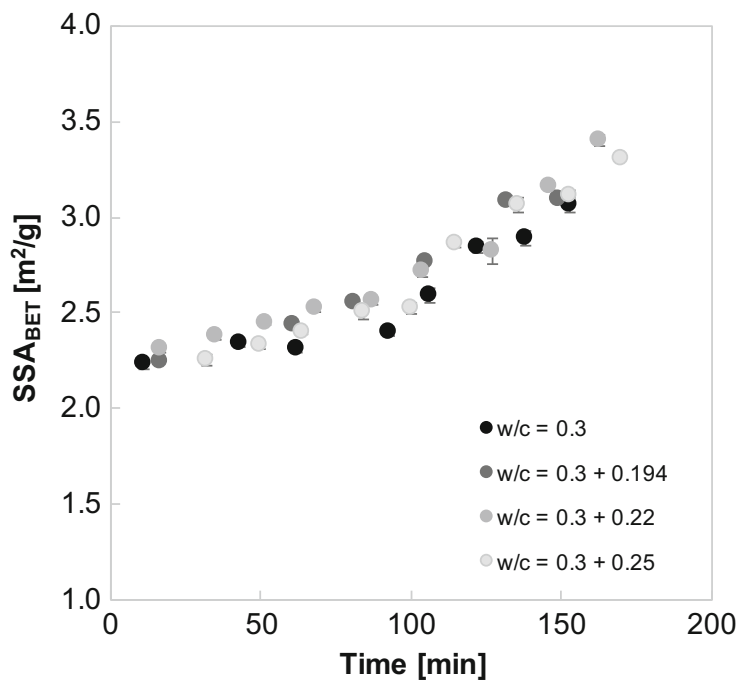

Fig. $5 \mathrm{SSA}_{\mathrm{BET}}$ evolution of reference pastes at different final $w / c$ ratios. The results are shown as the mean values and the standard deviation of the mean for $n_{\text {samples }}=3$. The error bars are included, but often not visible because they are smaller than the data markers

important since it is during that period that cement undergoes a first substantial increase in $\mathrm{SSA}_{\mathrm{BET}}$, mainly due to the precipitation of ettringite [19]. 
3.3 Relation between yield stress and heat rate

\subsubsection{Basic observations}

Experiments indicate that hydration kinetics measured by isothermal calorimetry and the yield stress evolution are strongly correlated, as shown in Fig. 6. This is most evident when plotting the yield stress versus either the heat rate or versus the cumulative heat (Online Resource 3). Two zones can be identified: in the first one, the yield stress is roughly constant (horizontal in the green-shaded zoomed zone in Fig. 6), whereas it increases exponentially with heat rate in the second yellowish zone.

The point at which the two regimes intersect is defined as onset and the time when this occurs is defined as onset time, $t_{\mathrm{OS}}$. Beyond this, the fluidity is lost at a substantial rate. The two arrows in Fig. 7 indicate the direction of increasing time for each zone: they have opposite directions in the plot of the heat rate because the heat rate first decreases and then increases. Plots related to the cumulative heat data are reported in Online Resource 3. A more careful analysis of the data shows that the best exponential fits are obtained with the heat rate rather than the cumulative one. Therefore, in what follows, we will report yield stress versus heat rate.

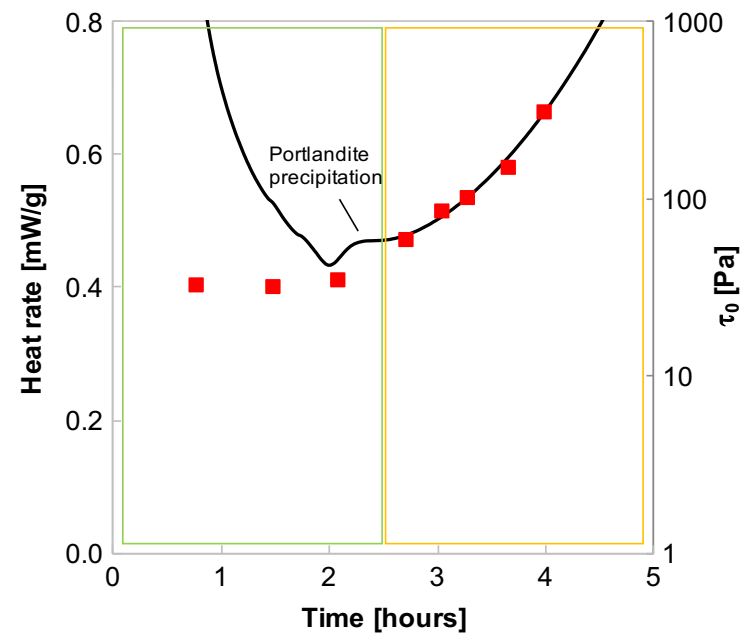

Fig. 6 Heat rate (black line) and yield stress evolution (red squares) for an OPC paste with 2.5PMA2000 dosed at $2 \mathrm{mg} / \mathrm{g}$ over the first $5 \mathrm{~h}$. The green-shaded area corresponds to the period when the yield stress is roughly constant, whereas the orange-shaded area shows the yield stress increasing exponentially with the heat rate. (Color figure online)

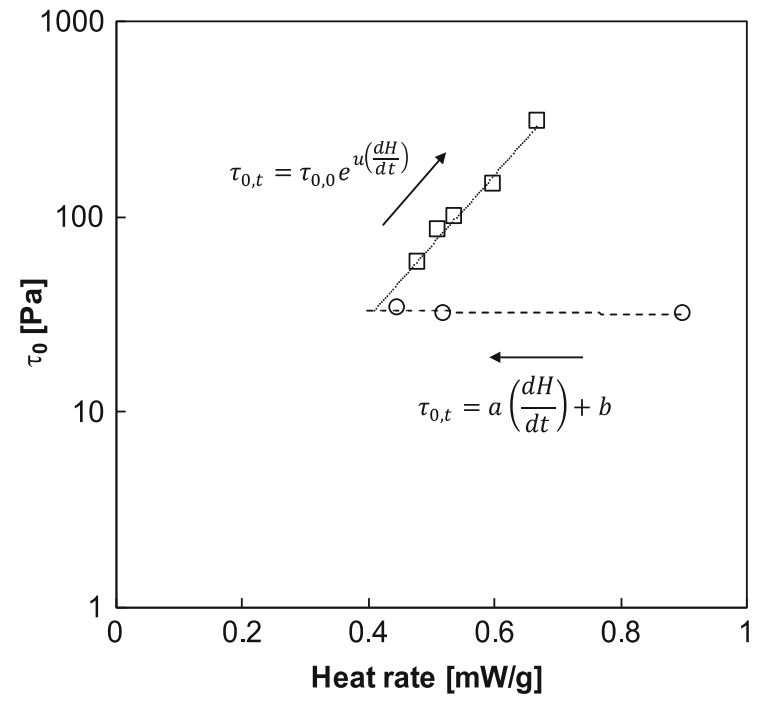

Fig. 7 Graphical representation of the relation of yield stress versus heat rate. The used polymer is 2.5PMA2000 dosed at $2 \mathrm{mg} / \mathrm{g}$. The arrows indicate the time evolution

\subsubsection{From yield stress back to spread diameters}

As explained above, we generally find that the exponential function of the heat rate fits very well the yield stress:

$\tau_{0, t}=\tau_{0,0} \cdot \exp \left(u \cdot \frac{\mathrm{d} H}{\mathrm{~d} t}\right)$

where $\tau_{0, t}$ is the yield stress at the different tested times, $\frac{\mathrm{d} H}{\mathrm{~d} t}$ is the heat rate and $u$ represents the yield stress gain coefficient and $\tau_{0,0}$ is the yield stress extrapolated to $\mathrm{d} H / \mathrm{d} t=0$.

As explained in the Sect. 2.3, yield stress can be obtained from spread flow test using an exponential function of the spread flow diameter $D$ (Eq. 3), where $a$ and $b$ are constant values corresponding to 0.3480 and 7.9473, respectively.

Therefore, we write $\tau_{0,0}$ as:

$\tau_{0,0}=\exp \left(b-a D_{0,0}\right)$

Equations 3, 7 and 8 can be combined to give:

$\exp \left(b-a \cdot D_{t}\right)=\exp \left(b-a \cdot D_{0,0}\right) \cdot \exp \left(u \cdot \frac{\mathrm{d} H_{t}}{\mathrm{~d} t}\right)$

where $D_{0,0}$ is the spread diameter corresponding to the extrapolated yield stress $\tau_{0,0}$. 
This gives the spread diameter $D_{t}$ at time $t$ as:

$D_{t}=D_{0,0}-v \cdot \frac{\mathrm{d} H_{t}}{\mathrm{~d} t}$

with $v$ being the rate of flow loss coefficient given by:

$v=\frac{u}{a}$

Equation 10 expresses the fact that, since the yield stress is an exponential function of both the spread diameter and the heat rate, then a linear relation should exist between spread diameter and heat rate, as illustrated in Fig. 8.

Figure 8 underlines that $D_{0,0}$, and therefore also $\tau_{0,0}$, are just extrapolated values, which by themselves do not have a physical meaning, but are useful fitting parameters to determine. In each fit used to determine these parameters, data points of spread diameters smaller than $6.5 \mathrm{~cm}$-corresponding to very high yield stress values-were generally excluded as they tended to depart from the exponential fit. The fact that those points do not fit the selected regression function may have a physical origin due to changes in rate laws, but we rather attribute this to the lower accuracy of

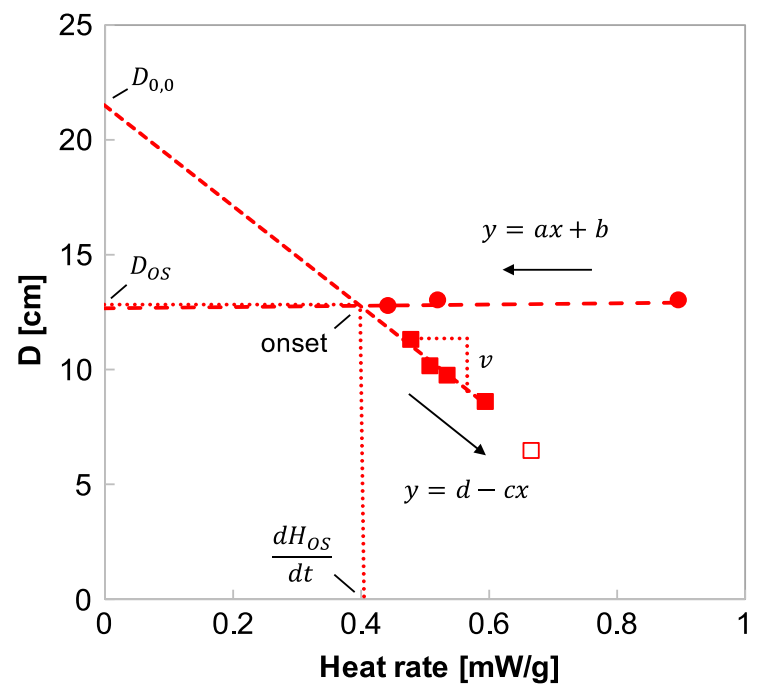

Fig. 8 Graphical representation of spread diameters with respect to heat rate for an OPC paste with the polymer 2.5 PMA2000 initially dosed at $2 \mathrm{mg} / \mathrm{g}$. The intercept $D_{0,0}$ and the slope $v$ of the linear regression of $D$ versus heat rate in the acceleration period are shown. The arrows indicate the time evolution. The diameter $\left(D_{\mathrm{OS}}\right)$ and $\left(\mathrm{d} H_{\mathrm{OS}} / \mathrm{d} t\right)$ at the onset are obtained at the intersection of the two regime curves. The empty symbol in at very small spread flow was excluded from the fit calculation yield stress prediction from low spread measurements. Additionally, for very large spreads, the contribution from the surface tension to flow spreads is only calculated with a rather crude approximation. Therefore, here also the accuracy of the exponential relation between flow spread and yield stress can be questioned.

\subsubsection{Determination of the onset point}

Our data clearly show that there must be a moment during hydration when a real change of regime occurs, probably caused by a critical event that leads to an acceleration of the hydration. We refer such a moment as onset and use the subscript OS to refer to it.

For our analysis we first determine the values of $D_{\mathrm{OS}}$, and therefore the yield stress $\tau_{0, \mathrm{OS}}$, as well as the heat rate $\frac{\mathrm{d} H_{\text {OS }}}{\mathrm{d} t}$ by using the intersections between both regimes on the plots of spread diameters versus heat rate (Fig. 8). In the calculation that will follow, the yield stresses are normalized with respect to it. Those values are then reported with respect to the increase of heat rate after the onset as $\frac{\mathrm{d} H_{t}}{\mathrm{~d} t}-\frac{\mathrm{d} H_{\mathrm{OS}}}{\mathrm{d} t}$.

In addition to the heat rate and the yield stress at the onset, it is necessary to determine the exact time of the onset $\left(t_{\mathrm{OS}}\right)$, which is a more delicate step. Indeed, it would a priori be useful to use the continuous calorimetric measurements to identify that time when the increase of the value of $\frac{\mathrm{d} H_{\mathrm{OS}}}{\mathrm{d} t}$ occurs. Unfortunately, around the onset, portlandite may nucleate causing a non-monotonic evolution of the heat rate as shown in Fig. 6. This means that the heat rate at the onset, $\frac{\mathrm{d} H_{\mathrm{OS}}}{\mathrm{d} t}$, may be found at different times over a short period, but only one of these corresponds to the real onset time. We resolved this issue using linear fits of the spread diameter versus time to extrapolate $t_{\mathrm{OS}}$ in correspondence to $D_{\mathrm{OS}}$ from Fig. 8. The combination of values of $D_{\mathrm{OS}}, \tau_{0, \mathrm{OS}}, \frac{\mathrm{d} H_{\mathrm{OS}}}{\mathrm{d} t}, t_{0, \mathrm{OS}}, \mathrm{SSA}_{\mathrm{OS}}$ are summarized in Table 2 .

\subsection{Conditions at the onset time $\left(t_{\mathrm{OS}}\right)$}

Figure 9 shows that the onset time linearly increases with the number of charges introduced in the system. The intercept from the linear regression corresponds to the time at the onset in absence of polymer, $t_{\mathrm{OS}}^{\mathrm{ref}}$. This value (around $68 \mathrm{~min}$ in this specific case) is 
Table 2 Summary of the main parameters at the onset point

\begin{tabular}{|c|c|c|c|c|c|c|}
\hline \multicolumn{2}{|l|}{ PCE } & \multirow{2}{*}{$\mathrm{d} H_{\mathrm{OS}} / \mathrm{d} t$ (mW/g cement) } & \multirow[t]{2}{*}{$D_{\mathrm{OS}}(\mathrm{cm})$} & \multirow[t]{2}{*}{$\tau_{0}(\mathrm{~Pa})$} & \multirow[t]{2}{*}{$t_{\mathrm{OS}}(\min )$} & \multirow[t]{2}{*}{$\mathrm{SSA}_{\mathrm{OS}}\left(\mathrm{m}^{2} / \mathrm{g}\right)$} \\
\hline Type & Dosage (mg/g cement) & & & & & \\
\hline \multirow[t]{3}{*}{ 2.5PMA1000 } & 2 & 0.32 & 17.2 & 7.1 & 183 & $2.20 \pm 0.03$ \\
\hline & 3 & 0.31 & 21.3 & 1.7 & 265 & $2.04 \pm 0.03$ \\
\hline & 4 & 0.30 & 22.7 & 1.1 & 337 & $1.84 \pm 0.03$ \\
\hline \multirow[t]{3}{*}{ 2.5PMA2000 } & 2 & 0.44 & 13.7 & 24.9 & 135 & $2.18 \pm 0.02$ \\
\hline & 3 & 0.41 & 18.0 & 5.4 & 171 & $2.13 \pm 0.02$ \\
\hline & 4 & 0.39 & 21.0 & 1.9 & 222 & n.d. \\
\hline \multirow[t]{2}{*}{ 2.5PMA5000 } & 1.78 & 0.45 & 13.1 & 29.6 & 88 & n.d. \\
\hline & 2.67 & 0.38 & 22.0 & 1.3 & 106 & n.d. \\
\hline \multirow[t]{3}{*}{ 4.0PMA1000 } & 1 & 0.31 & 14.3 & 19.4 & 159 & $2.07 \pm 0.01$ \\
\hline & 1.25 & 0.23 & 20.5 & 2.2 & 175 & n.d. \\
\hline & 1.5 & 0.23 & 22.0 & 1.3 & 235 & $1.96 \pm 0.02$ \\
\hline \multirow[t]{2}{*}{ 4.0PMA2000 } & 1 & 0.41 & 13.5 & 26.0 & 105 & n.d. \\
\hline & 1.5 & 0.35 & 20.3 & 2.4 & 172 & n.d. \\
\hline
\end{tabular}

The heat rate and the diameter at the onset were extrapolated at the intersection of the two regime curves, as shown in Fig. 8. The yield stress was calculated by using the updated version of Eq. 3. $t_{\mathrm{OS}}$ is extrapolated by the linear fit of spread diameter versus time in correspondence of $D_{\mathrm{OS}}$

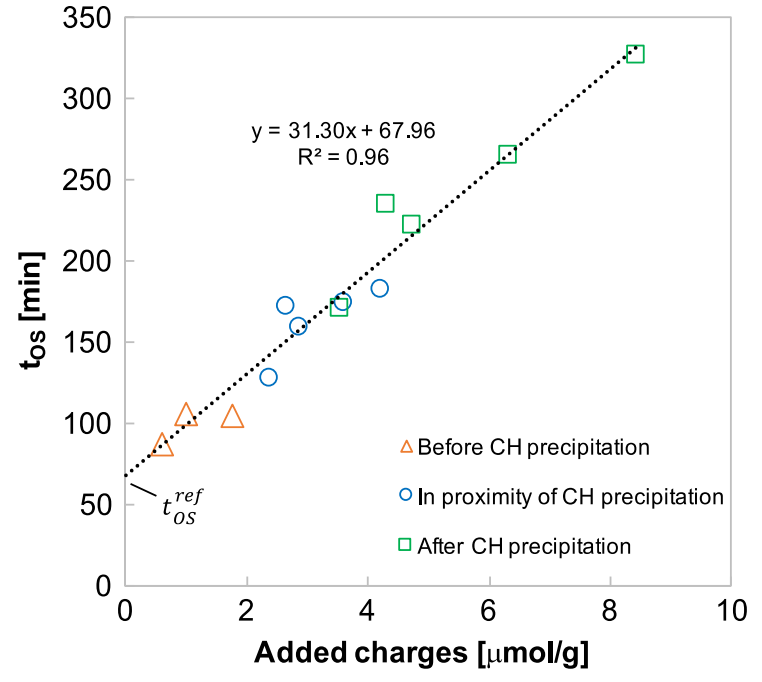

Fig. 9 Time at the onset in relation to the portlandite $(\mathrm{CH})$ precipitation, as identified by isothermal calorimetry by varying the number of added charges. The extrapolation of the time at the intercept corresponds to the estimated time at the onset $\left(t_{\mathrm{OS}}^{\mathrm{ref}}\right)$ in absence of PCEs

considered a good estimation because it occurs at the transition between the induction and the acceleration period (Fig. 1). Very interestingly, the occurrence of the onset seems to be independent of the time when the portlandite precipitates. Indeed, Fig. 9 shows that, for a low amount of charges, the onset occurs before the portlandite precipitation, whereas for a large number of charges the onset starts after portlandite precipitation.

\subsection{Relation between hydration kinetics and surface area evolution}

An important contribution of this work is to study flow loss in relation to changes in specific surface area. Since the latter are driven by hydration, it makes sense to study their quantitative relationship, although this is not necessarily intuitive. Rather, a relation to specific surface might appear more natural for yield stress since this property depends on surface forces between particles.

As shown in Fig. 10, there is a relation between heat rate and specific surface after the onset, both with and without PCEs. This is shown for three polymers, for a total of seven dosages, and four mixes without PCE. The data points look more scattered at low values. However, in those cases the estimation of the parameters of the onset is more delicate, mainly at low dosages of PCE. Also, in absence of polymer, 

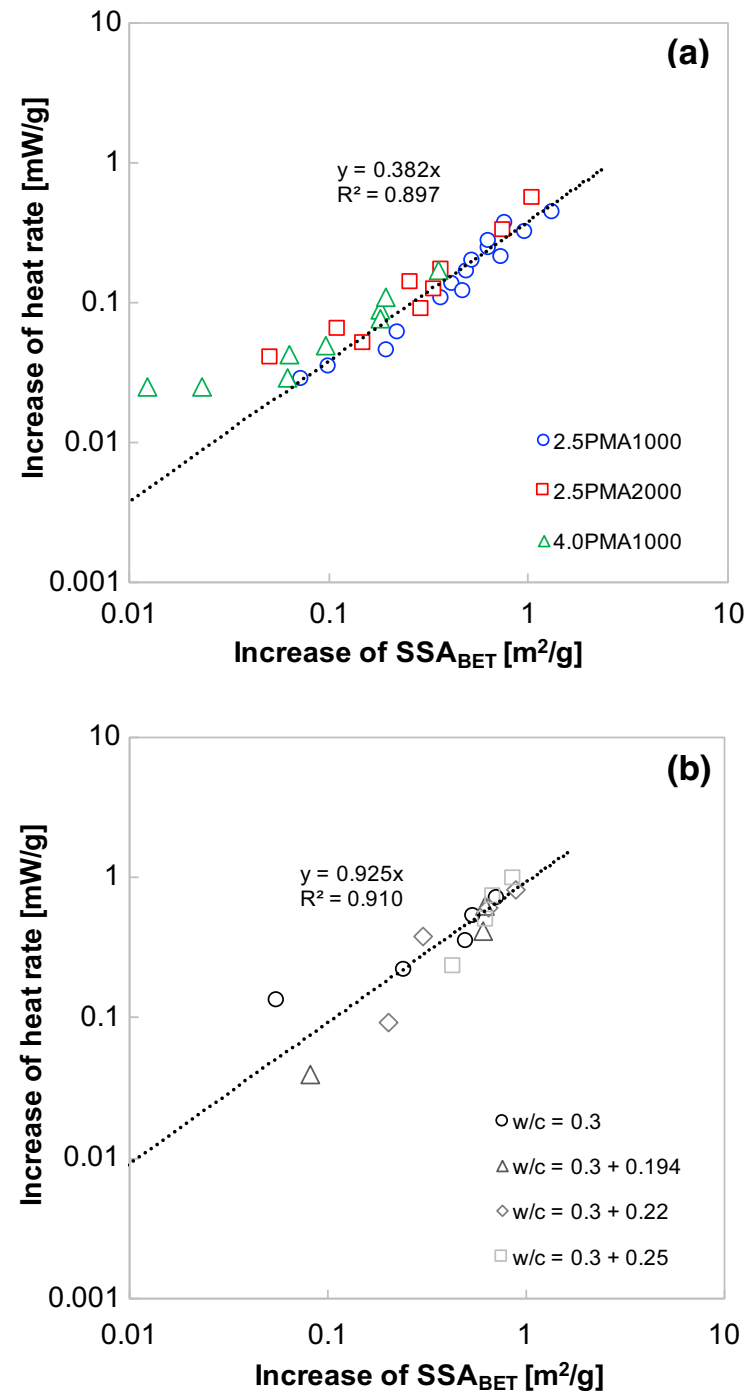

Fig. 10 Increase of the heat rate in relation to the increase of the $\mathrm{SSA}_{\mathrm{BET}}$ after the onset: $\mathbf{a}$ in superplasticized mixes for a total of 7 dosages with 3 different polymers and $\mathbf{b}$ for plain mixes with 4 different final $w / c$ ratios

both $\frac{\mathrm{d} H_{\mathrm{OS}}}{\mathrm{d} t}$ and $\mathrm{SSA}_{\mathrm{OS}}$ have been extrapolated from Fig. 9.

The slope of this linear relation between heat rates and specific surfaces in presence of PCEs (Fig. 10a) is almost half of that obtained from the reference mixes not containing PCEs (Fig. 10b). This can be seen as a result from PCEs slowing down dissolution, which, in turn, leads to an inhibition of the growth of the specific surface.

Importantly, Fig. 10a also shows up that this relation does not depend on polymer type or dosage.
In any of these cases, we will however consider that we have the following general relation:

$\frac{\mathrm{d} H_{t}}{\mathrm{~d} t}-\frac{\mathrm{d} H_{\mathrm{OS}}}{\mathrm{d} t}=\gamma\left(\mathrm{SSA}_{t}-\mathrm{SSA}_{\mathrm{OS}}\right)$

where $\left(\mathrm{SSA}_{t}-\mathrm{SSA}_{\mathrm{OS}}\right)$ is the increase of $\mathrm{SSA}_{\mathrm{BET}}$ after the onset, $\gamma$ (in $\mathrm{mW} / \mathrm{m}^{2}$ ) is the slope corresponding of $0.382 \mathrm{~mW} / \mathrm{m}^{2}$ in presence of PCEs and 0.925 $\mathrm{mW} / \mathrm{m}^{2}$ in their absence.

\section{Discussion}

Most of the data analysis reported in the literature attempts to directly express yield stress as a function of time, as shown in Fig. 3. In this work, for the first time, by the combination of the yield stress calculation and calorimetric data, two distinct regimes can be identified leading to an original correlation, where the evolution of the yield stress is not studied only with respect to time, but rather with respect to the evolution of meaningful physical properties of the system. Doing so, no hypothesis is needed about the effect of PCEs on hydration kinetics, because the focus is on the consequence of this change of kinetics. Specifically, we want to see how the specific surface is changed and, consequently, the yield stress evolves.

The advantage in studying superplasticized pastes is that a very clear transition from one regime to another can be detected. An important observation is that data in the acceleration period cannot be adequately fit by superposing two processes that would both take place over the whole course of hydration. Rather, after the onset, the yield stress seems to be amplified by hydration in a way and to an extent that does not occur before. From this perspective, it only makes sense to discuss our data by including the notion of onset.

\subsection{Induction period or constant regime}

During the induction period, a low and roughly linear evolution of the yield stress is observed (Fig. 7), although a moderate rise would be expected due to thixotropy at rest, during which $\mathrm{C}-\mathrm{S}-\mathrm{H}$ bridges constantly form [10-12, 45, 46].

Roussel [11, 46] defined the constant rate for the increase of yield stress $\tau_{0}$ during a resting time $t_{\text {rest }}$ as flocculation rate, $A_{\text {thix }}$ : 
$\frac{\tau_{0, t}}{\tau_{0,0}}=1+\frac{A_{\text {thix }}}{\tau_{0,0}} t_{\text {rest }}$

While this equation describes an evolution of the yield stress at rest, the procedure in our experiments "refreshes" the cement paste, by remixing it with an equivalent intensity (at least the same mixing rate and duration for all the samples) before spread measurements. In this way, thixotropic effects can be neglected, which allows us to focus on the impact of hydration reactions.

We infer that no irreversible structural build-up takes place during the induction period, although isothermal calorimetry data shows that some reactions take place. Our claim is supported by the fact that yield stress $\left(\tau_{0, t}\right)$ normalized by its value just after the mixing at $t_{0}\left(\tau_{0,0}\right)$ runs independently to the heat rate for seven mixes using three different PCEs (Fig. 11). A similar relationship for the cumulative heat is presented in Online Resource 3.

During the induction period, various factors affect the yield stress, such as particle size distribution of cement, polymer structure and dosage. Specific surface area of hydrating cement also plays a role, but it cannot account alone for the effect of different polymer structures and dosages on the yield stress of a given cement. Indeed, in this initial hydration period, the specific surface area remains rather constant and is

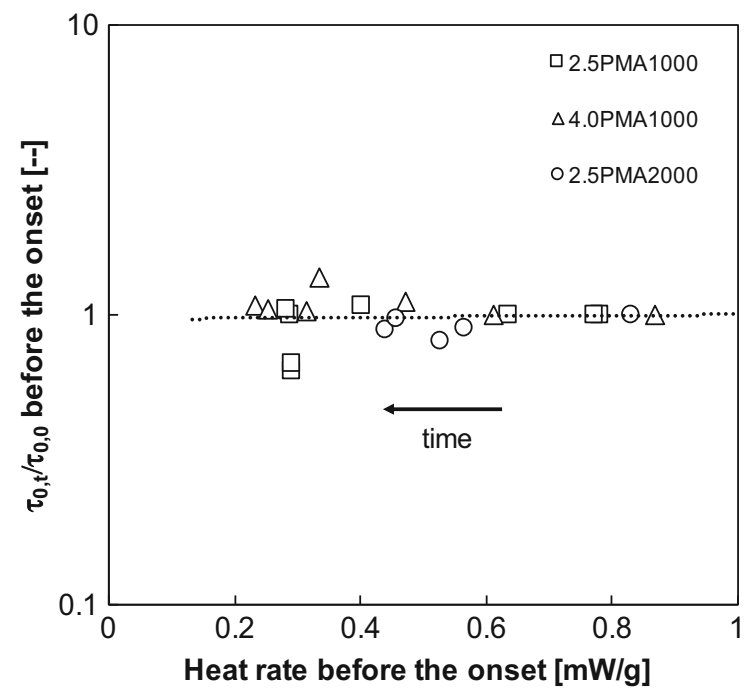

Fig. 11 Relation between the yield stress normalized with respect to the initial yield stress after mixing and heat rate before the onset. Arrows show the direction of increasing time. The discontinuous line is drawn as a guide for the eye not dependent on heat rate as shown in Fig. 12. However, its evolution becomes relevant at later times (Figs. 4 and 5), likely after the onset.

\subsection{Onset or transition point}

The timing of the occurrence of the onset is linked to the retarding effect of PCEs. In this context, it was recently reported that in direct addition, a critical PCE concentration can be derived, after which the retardation, $\Delta t$, increases linearly with the number of charged functional groups interacting with the silicate phases $[20,47]$. In contrast, the onset time is purely proportional to the dosed charges. This linearity resembles the case of delayed addition recently reported for a model cement by Marchon et al. [20, 47]. However, here the slope of this regression is the same for all polymers and does not show a dependence on C/E. This difference may be due to the fact that the polymers used in the present work were produced by copolymerization rather than grafting. Alternatively, it could be due to the fact that our experiments were carried out in direct rather than indirect addition. The fact that there is no apparent "lost polymer", as in the case of direct addition by Marchon et al., suggests that the amount of polymer "consumed" by aluminates is very low, when compared to the used dosages. This might be due to the high content of the $\mathrm{C}_{3} \mathrm{~A}$ in the

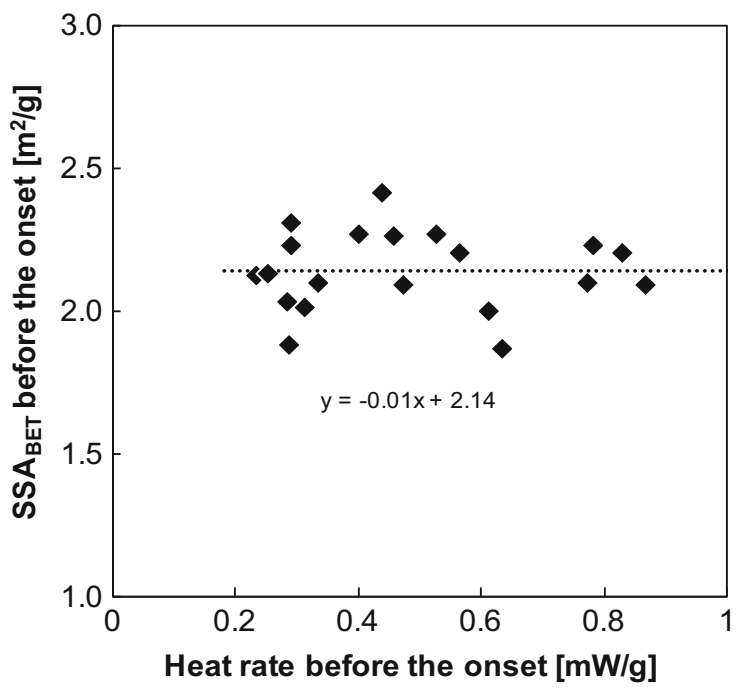

Fig. 12 Relation between $\mathrm{SSA}_{\mathrm{BET}}$ and heat rate before the onset, both before the onset, for 13 mixes prepared using five PCEs having different molecular structures 
model cement used by those authors $(20 \%)$ in contrast with the moderate amount in the industrial cement used here (about 6\%).

As recently demonstrated by several authors [47-49], PCEs preferentially block highly reactive surfaces, characterized by defects in form of kinks and etch pits, limiting the step retreat process. We confirm this theory on the basis of two independent considerations. Firstly, it is noted from Table 2 that, for a given polymer, the heat rate at the onset decreases by increasing the number of charges. This confirms that PCEs slow down the dissolution of cement phases in relation to their molecular structure [47]. Secondly, the initial $\mathrm{SSA}_{\mathrm{BET}}$ decreases when the polymer dosage is increased, as shown in the same table. This suggests that PCEs block the opening of etch pits and roughening of the cement grains more than promoting the nucleation of ettringite. Therefore, it seems that our PCEs adsorb both on ettringite and silicates from the beginning of the hydration. This contrasts with the study by Marchon et al., who found, in a model cement and direct addition, that at low dosages polymers are fully mobilized on ettringite [20, 47]. On that basis, they considered the specific surface of hydrates formed as the surface on which polymers adsorb. In our case, however, it is more appropriate to consider that adsorption takes place on all cement phases.

Portlandite nucleation and precipitation have been suggested as a possible trigger for the accelerated hydration rate $[50,51]$. It is very often observed as a small bump in calorimetric curves at the end of the induction period $[50,52]$. However, while portlandite precipitation might explain the beginning of the acceleration period in plain mixes where the induction period is extremely short, it seems unrelated to the onset in presence of PCEs. Indeed, we evidence that the onset can appear even several hours after the portlandite precipitation when high polymer dosages are used, as shown in Fig. 9. We infer therefore that the transition between the induction and the acceleration periods might be controlled by the initiation of nucleation and growth of hydrates or by the ending dissolution inhibition.

\subsection{Acceleration period or exponential regime}

Various authors have reported an exponential increase of the yield stress over time [38, 45, 53-55]. In many cases, there is no clear distinction between the induction period and the acceleration period, but an attempt to describe the overall evolution by a single expression. For example, Perrot et al. [56] recently proposed the following expression for the normalized yield stress as:

$\frac{\tau_{0, t}}{\tau_{0,0}}=\frac{A_{\text {thix }}}{\tau_{0,0}} t_{\mathrm{c}}\left(e^{t / t_{\mathrm{c}}}-1\right)+1$

where $t_{\mathrm{c}}$ is a fitting parameter defined as characteristic time.

Linearization of the above equation for short times (typically from seconds to minutes $[10,56]$ ) leads to Eq. 13. In the induction period, it was evidenced that hydration does not lead to irreversible changes and, therefore, the above equation must relate to thixotropy. However, after the onset, the exponential increase of the yield stress with respect to the heat rate describes an irreversible change. The intermixing of these two phenomena (reversible and irreversible ones) in a single equation, therefore, may fit data well, but cannot provide physical insight. The present experiments clearly identify the existence of an onset that indicates the start of a new process leading to an exponential increase of yield stress. In contrast to the existing literature, the introduction of this new parameter defines the guidelines of an original approach for tackling the question of flow loss.

In the present work, we evidence an exponential relation between yield stress and hydration kinetics in the acceleration period (Fig. 7). A similar exponential relation is found between yield stress and specific surface area, additionally showing the same dependence on the polymer structure and dosage. Here, we emphasize that it is quite understandable and expected that yield stress should increase with specific surface. However, understanding the nature of such increase and its relation to PCE type and dosage is a more complex problem, that has been treated by Mantellato [27] and planned to be covered in subsequent papers.

For this paper, it is worth highlighting that the above relations imply that there is a direct proportionality between the increase in specific surface area and the increase of heat rate during the acceleration period, as illustrated in Fig. 10. This may result from dissolution control, but more probably reflects a boundary nucleation and growth nature of the acceleration period [57-61]. Because surface formation is so important in those theories, we believe that the 
result in Fig. 10 should be a great interest to research on cement hydration. Specifically, for experimentalists, the protocols and methodology presented should make possible to more reliably identify the onset of the acceleration period than has been previously possible for cement pastes.

Finally, we note that in absence of PCEs, we also find a direct proportionality between the increase of the heat rate, $\left(\frac{\mathrm{d} H_{t}}{\mathrm{~d} t}-\frac{\mathrm{d} H_{\mathrm{OS}}}{\mathrm{d} t}\right)$ and the increase of the specific surface area, $\left(\mathrm{SSA}_{t}-\mathrm{SSA}_{\mathrm{OS}}\right)$ as shown in Fig. 10b. However, the proportionality constant is not the same as in presence of PCEs. We are not yet sure of the reason for this discrepancy, but tentatively attribute it to a difference in the balance between heterogeneous and homogenous nucleation. Various studies indeed support the view that PCEs increase the proportion of homogenous nucleation events at the expense of heterogeneous nucleation that is dominant in their absence [62-65].

\subsection{Considerations about the onset time}

The onset time has a special significance in practice as it defines the duration of the open time, but it is also paradoxically difficult to determine reliably with simple tests. Various attempts to do so include the measurements of setting time by Vicat test [66], force measurements by penetrometers [67], Ultrasonic Pulse Velocity [68, 69] and Electrical Resistivity [70] tests. However, it is well known that these empirical tests are not always able to capture even major differences occurring in hydrating systems when they are conducted out of the range of standard procedures, mainly in presence of PCEs [8]. Therefore, it worth noting that the time at the onset might correspond to the setting time measured with the previously mentioned tests.

Indeed, these generally all rely on an analysis of the time evolution of these measurements to determine the onset time, which involves some ambiguities, because the transition from one regime to another is not generally very sharp in time. Conversely, in this paper, it was shown how the onset time can then be unambiguously extracted from a calorimetry curve once the onset point has been identified by the specific combination of yield stress and heat rate as in Fig. 7.

\section{Conclusions}

Thanks to the presented analytical methods, it was possible to establish a strong correlation between yield stress evolution and hydration kinetics expressed as heat rate after the onset. The presented data clearly identify the existence of an onset that indicates the start of a new process leading to an exponential increase of yield stress in relation to heat rate. This marks a very clear difference with the existing literature and highlights the originality of this work.

This paper also shows that the onset is not caused by the precipitation of portlandite.

More interestingly, two distinct processes are shown to occur before and after the onset. For the first time, we could examine them individually, showing different dependencies on hydration kinetics that cannot be described by a single expression. In this way, it was demonstrated that, during the induction period, the linear evolution of the yield stress is independent of hydration reactions and, therefore, can be referred to as thixotropy. In contrast, after the onset, the exponential increase of the yield stress is proportional to the heat rate, describing an irreversible structural build-up. In turn, in the same timeframe, an exponential dependence of yield stress with the increase in specific surface was also found. This result can be more directly understood because yield stress derives from interparticle forces.

Importantly, the two exponential relations mentioned above imply that in the acceleration period there is a direct proportionality between the increase in specific surface and the increase in heat rate. This important experimental result most likely points to the nucleation and growth nature of the acceleration period. The procedures presented in this paper may therefore become important for kinetic studies of cement hydration for which a better isolation of the acceleration period may be needed than has been possible up to now.

Acknowledgements Funding for Sara Mantellato was provided by the SNSF Project (No. 140615) titled "Mastering flow loss of cementitious systems" and the SNSF National Centre for Competence in Research in Digital FabricationInnovative Building Processes in Architecture. The authors wish to thank Lukas Frunz (SIKA AG Schweiz) for providing the polymers and Giulia Gelardi (ETH Zürich) for their characterization. 


\section{Compliance with ethical standards}

Conflict of interest The authors declare that they have no conflict of interest.

Open Access This article is distributed under the terms of the Creative Commons Attribution 4.0 International License (http:// creativecommons.org/licenses/by/4.0/), which permits use, duplication, adaptation, distribution and reproduction in any medium or format, as long as you give appropriate credit to the original author(s) and the source, provide a link to the Creative Commons license and indicate if changes were made.

\section{References}

1. Flatt RJ (2004) Towards a prediction of superplasticized concrete rheology. Mater Struct 37:289-300. https://doi. org/10.1007/BF02481674

2. Yamada K, Takahashi T, Hanehara S, Matsuhisa M (2000) Effects of the chemical structure on the properties of polycarboxylate-type superplasticizer. Cem Concr Res 30: 197-207. https://doi.org/10.1016/S0008-8846(99)00230-6

3. Vickers TM Jr, Farrington SA, Bury JR, Brower LE (2005) Influence of dispersant structure and mixing speed on concrete slump retention. Cem Concr Res 35:1882-1890. https://doi.org/10.1016/j.cemconres.2005.04.013

4. Uchikawa H, Sawaki D, Hanehara S (1995) Influence of kind and added timing of organic admixture on the composition, structure and property of fresh cement paste. Cem Concr Res 25:353-364. https://doi.org/10.1016/0008-8846 (95)00021-6

5. Aiad I (2003) Influence of time addition of superplasticizers on the rheological properties of fresh cement pastes. Cem Concr Res 33:1229-1234. https://doi.org/10.1016/S00088846(03)00037-1

6. Han D, Ferron RD (2016) Influence of high mixing intensity on rheology, hydration, and microstructure of fresh state cement paste. Cem Concr Res 84:95-106. https://doi.org/ 10.1016/j.cemconres.2016.03.004

7. Zhang M-H, Sisomphon K, Ng TS, Sun DJ (2010) Effect of superplasticizers on workability retention and initial setting time of cement pastes. Constr Build Mater 24:1700-1707. https://doi.org/10.1016/j.conbuildmat.2010.02.021

8. Nkinamubanzi P-C, Mantellato S, Flatt RJ (2016) 16-Superplasticizers in practice. In: Aïtcin P-C, Flatt RJ (eds) Science and technology of concrete admixtures. Woodhead Publishing, Sawston, pp 353-377

9. Barnes HA (1997) Thixotropy-a review. J Non Newton Fluid Mech 70:1-33. https://doi.org/10.1016/S0377-0257 (97)00004-9

10. Roussel N, Ovarlez G, Garrault S, Brumaud C (2012) The origins of thixotropy of fresh cement pastes. Cem Concr Res 42:148-157. https://doi.org/10.1016/j.cemconres.2011.09. 004

11. Roussel N (2006) A thixotropy model for fresh fluid concretes: theory, validation and applications. Cem Concr Res 36: 1797-1806. https://doi.org/10.1016/j.cemconres.2006.05.025

12. Tattersall GH, Banfill PFG (1983) The rheology of fresh concrete. Pitman Advanced Publishing Program, London
13. Kovler K, Roussel N (2011) Properties of fresh and hardened concrete. Cem Concr Res 41:775-792. https://doi.org/ 10.1016/j.cemconres.2011.03.009

14. Jiang SP, Mutin JC, Nonat A (1995) Studies on mechanism and physico-chemical parameters at the origin of the cement setting. I. The fundamental processes involved during the cement setting. Cem Concr Res 25:779-789. https://doi.org/ 10.1016/0008-8846(95)00068-N

15. Jiang SP, Mutin JC, Nonat A (1996) Studies on mechanism and physico-chemical parameters at the origin of the cement setting II. Physico-chemical parameters determining the coagulation process. Cem Concr Res 26:491-500. https:// doi.org/10.1016/S0008-8846(96)85036-8

16. Flatt RJ, Houst YF (2001) A simplified view on chemical effects perturbing the action of superplasticizers. Cem Concr Res 31:1169-1176. https://doi.org/10.1016/S00088846(01)00534-8

17. Giraudeau C, D'Espinose De Lacaillerie J-B, Souguir Z et al (2009) Surface and intercalation chemistry of polycarboxylate copolymers in cementitious systems. J Am Ceram Soc 92:2471-2488. https://doi.org/10.1111/j.1551-2916. 2009.03413.x

18. Plank J, Dai Z, Andres PR (2006) Preparation and characterization of new $\mathrm{Ca}-\mathrm{Al}-$ polycarboxylate layered double hydroxides. Mater Lett 60:3614-3617. https://doi.org/10. 1016/j.matlet.2006.03.070

19. Dalas F, Pourchet S, Rinaldi D et al (2015) Modification of the rate of formation and surface area of ettringite by polycarboxylate ether superplasticizers during early C3A$\mathrm{CaSO}_{4}$ hydration. Cem Concr Res 69:105-113. https://doi. org/10.1016/j.cemconres.2014.12.007

20. Delphine Marchon, Patrick Juilland, Emmanuel Gallucci et al (2017) Molecular and submolecular scale effects of comb-copolymers on tri-calcium silicate reactivity: toward molecular design. J Am Ceram Soc 100:817-841. https:// doi.org/10.1111/jace.14695

21. Meier MR, Rinkenburger A, Plank J (2016) Impact of different types of polycarboxylate superplasticisers on spontaneous crystallisation of ettringite. Adv Cem Res 28: 310-319. https://doi.org/10.1680/jadcr.15.00114

22. Pourchet S, Comparet C, Nonat A, Maitrasse P (2006) Influence of three types of superplasticizers on tricalciumaluminate hydration in presence of gypsum. In: Proceedings 8th CANMET/ACI international conference on superplasticizers and other chemical admixtures in concrete, Sorrento, ACI, SP-239, pp 151-168

23. Marchon D, Sulser U, Eberhardt A, Flatt RJ (2013) Molecular design of comb-shaped polycarboxylate dispersants for environmentally friendly concrete. Soft Matter 9:10719-10728. https://doi.org/10.1039/C3SM51030A

24. Prince W, Espagne M, Aïtcin P-C (2003) Ettringite formation: a crucial step in cement superplasticizer compatibility. Cem Concr Res 33:635-641. https://doi.org/10.1016/ S0008-8846(02)01042-6

25. Kreppelt F, Weibel M, Zampini D, Romer M (2002) Influence of solution chemistry on the hydration of polished clinker surfaces - a study of different types of polycarboxylic acid-based admixtures. Cem Concr Res 32: 187-198. https://doi.org/10.1016/S0008-8846(01)00654-8

26. Zingg A, Holzer L, Kaech A et al (2008) The microstructure of dispersed and non-dispersed fresh cement pastes-new 
insight by cryo-microscopy. Cem Concr Res 38:522-529. https://doi.org/10.1016/j.cemconres.2007.11.007

27. Mantellato S (2017) Flow loss in superplasticized cement pastes. Doctoral dissertation, ETH Zurich

28. Gelardi G, Sanson N, Nagy G, Flatt RJ (2017) Characterization of comb-shaped copolymers by multidetection SEC, DLS and SANS. Polymers 9:61. https://doi.org/10.3390/ polym9020061

29. Flatt RJ, Schober I, Raphael E et al (2009) Conformation of adsorbed comb copolymer dispersants. Langmuir 25: 845-855. https://doi.org/10.1021/la801410e

30. Wadsö L, Winnefeld F, Riding K, Sandberg P (2016) 2-Calorimetry. In: Scrivener K, Snellings R, Lothenbach B (eds) A practical guide to microstructural analysis of cementitious materials. Taylor \& Francis, pp 37-74

31. Mantellato S, Palacios M, Flatt RJ (2015) Reliable specific surface area measurements on anhydrous cements. Cem Concr Res 67:286-291. https://doi.org/10.1016/j.cemconres. 2014.10.009

32. Mantellato S, Palacios M, Flatt RJ (2016) Impact of sample preparation on the specific surface area of synthetic ettringite. Cem Concr Res 86:20-28. https://doi.org/10.1016/j. cemconres.2016.04.005

33. Saak AW, Jennings HM, Shah SP (2004) A generalized approach for the determination of yield stress by slump and slump flow. Cem Concr Res 34:363-371. https://doi.org/10. 1016/j.cemconres.2003.08.005

34. Murata J (1984) Flow and deformation of fresh concrete. Mater Constr 17:117-129. https://doi.org/10.1007/BF0247 3663

35. Pashias N, Boger DV, Summers J, Glenister DJ (1996) A fifty cent rheometer for yield stress measurement. J Rheol 40:1179-1189. https://doi.org/10.1122/1.550780

36. Clayton S, Grice TG, Boger DV (2003) Analysis of the slump test for on-site yield stress measurement of mineral suspensions. Int J Miner Process 70:3-21. https://doi.org/ 10.1016/S0301-7516(02)00148-5

37. Roussel N, Coussot P (2005) "Fifty-cent rheometer" for yield stress measurements: from slump to spreading flow. J Rheol (1978-Present) 49:705-718. https://doi.org/10. 1122/1.1879041

38. Flatt RJ, Larosa D, Roussel N (2006) Linking yield stress measurements: spread test versus Viskomat. Cem Concr Res 36:99-109. https://doi.org/10.1016/j.cemconres.2005. 08.001

39. Roussel N, Stefani C, Leroy R (2005) From mini-cone test to Abrams cone test: measurement of cement-based materials yield stress using slump tests. Cem Concr Res 35:817-822. https://doi.org/10.1016/j.cemconres.2004.07.032

40. Zimmermann J, Hampel C, Kurz C et al (2009) Effect of polymer structure on the sulfate-polycarboxylate competition. In: Proceedings of the 9th ACI international conference on superplasticizers and other chemical admixtures. pp 165-176

41. Pierre A, Lanos C, Estellé P (2013) Extension of spreadslump formulae for yield stress evaluation. Appl Rheol 23:63849

42. Regnaud L, Nonat A, Pourchet S et al (2006) Changes in cement paste and mortar fluidity after mixing induced by PCP: a parametric study. In: Proceedings of the 8th CANMET/ACI international conference on superplasticizers and other chemical admixtures in concrete, Sorrento, 20-23 Oct 2006, pp 389-408

43. Yamada K, Ogawa S, Hanehara S (2001) Controlling of the adsorption and dispersing force of polycarboxylate-type superplasticizer by sulfate ion concentration in aqueous phase. Cem Concr Res 31:375-383. https://doi.org/10.1016/ S0008-8846(00)00503-2

44. Flatt RJ, Zimmermann J, Hampel C et al (2009) The role of adsorption energy in the sulfate-polycarboxylate competition. Spec Publ 262:153-164

45. Lootens D, Jousset P, Martinie L et al (2009) Yield stress during setting of cement pastes from penetration tests. Cem Concr Res 39:401-408. https://doi.org/10.1016/j.cemconres. 2009.01.012

46. Roussel N (2005) Steady and transient flow behaviour of fresh cement pastes. Cem Concr Res 35:1656-1664. https:// doi.org/10.1016/j.cemconres.2004.08.001

47. Marchon D (2016) Controlling cement hydration though the molecular structure of comb copolymer superplasticizers. Doctoral dissertation, ETH

48. Suraneni P, Flatt RJ (2015) Use of micro-reactors to obtain new insights into the factors influencing tricalcium silicate dissolution. Cem Concr Res 78(Part B):208-215. https:// doi.org/10.1016/j.cemconres.2015.07.011

49. Nicoleau L, Bertolim MA (2016) Analytical model for the alite (C3S) dissolution topography. J Am Ceram Soc 99:773-786. https://doi.org/10.1111/jace.13647

50. Young JF, Tong HS, Berger RL (1977) Compositions of solutions in contact with hydrating tricalcium silicate pastes. J Am Ceram Soc 60:193-198. https://doi.org/10. 1111/j.1151-2916.1977.tb14104.x

51. Bullard JW, Flatt RJ (2010) New insights into the effect of calcium hydroxide precipitation on the kinetics of tricalcium silicate hydration. J Am Ceram Soc 93:1894-1903. https://doi.org/10.1111/j.1551-2916.2010.03656.x

52. Kumar A, Bishnoi S, Scrivener KL (2012) Modelling early age hydration kinetics of alite. Cem Concr Res 42:903-918. https://doi.org/10.1016/j.cemconres.2012.03.003

53. Subramaniam KV, Wang $X$ (2010) An investigation of microstructure evolution in cement paste through setting using ultrasonic and rheological measurements. Cem Concr Res 40:33-44. https://doi.org/10.1016/j.cemconres.2009. 09.018

54. Lecompte T, Perrot A (2017) Non-linear modeling of yield stress increase due to SCC structural build-up at rest. Cem Concr Res 92:92-97. https://doi.org/10.1016/j.cemconres. 2016.11.020

55. Bellotto M (2013) Cement paste prior to setting: a rheological approach. Cem Concr Res 52:161-168. https://doi. org/10.1016/j.cemconres.2013.07.002

56. Perrot A, Pierre A, Vitaloni S, Picandet V (2014) Prediction of lateral form pressure exerted by concrete at low casting rates. Mater Struct 48:2315-2322. https://doi.org/10.1617/ s11527-014-0313-8

57. Juilland P, Gallucci E, Flatt R, Scrivener K (2010) Dissolution theory applied to the induction period in alite hydration. Cem Concr Res 40:831-844. https://doi.org/10. 1016/j.cemconres.2010.01.012

58. Nicoleau L, Nonat A, Perrey D (2013) The di- and tricalcium silicate dissolutions. Cem Concr Res 47:14-30. https://doi.org/10.1016/j.cemconres.2013.01.017 
59. Bullard JW, Scherer GW, Thomas JJ (2015) Time dependent driving forces and the kinetics of tricalcium silicate hydration. Cem Concr Res 74:26-34. https://doi.org/10. 1016/j.cemconres.2015.03.016

60. Garrault S, Nonat A (2001) Hydrated layer formation on tricalcium and dicalcium silicate surfaces: experimental study and numerical simulations. Langmuir 17:8131-8138. https://doi.org/10.1021/la011201z

61. Thomas JJ, Jennings HM, Chen JJ (2009) Influence of nucleation seeding on the hydration mechanisms of tricalcium silicate and cement. J Phys Chem C 113:4327-4334. https://doi.org/10.1021/jp809811w

62. Valentini L, Favero M, Dalconi MC et al (2016) Kinetic model of calcium-silicate hydrate nucleation and growth in the presence of PCE superplasticizers. Cryst Growth Des 16:646-654. https://doi.org/10.1021/acs.cgd.5b01127

63. Artioli G, Valentini L, Voltolini M et al (2015) Direct imaging of nucleation mechanisms by synchrotron diffraction micro-tomography: superplasticizer-induced change of C-S-H nucleation in cement. Cryst Growth Des 15:20-23. https://doi.org/10.1021/cg501466z

64. Garrault-Gauffinet S, Nonat A (1999) Experimental investigation of calcium silicate hydrate $(\mathrm{C}-\mathrm{S}-\mathrm{H})$ nucleation. J Cryst Growth 200:565-574. https://doi.org/10.1016/ S0022-0248(99)00051-2
65. Stark J, Möser B, Bellmann F (2007) Nucleation and growth of C-S-H phases on mineral admixtures. In: Grosse CU (ed) Advances in construction materials 2007. Springer, Berlin, pp 531-538

66. ASTM C191 (2008) Standard test methods for time of setting of hydraulic cement by Vicat needle. ASTM International, West Conshohocken

67. ASTM C403/C403M (2016) Standard test method for time of setting of concrete mixtures by penetration resistance. ASTM International, West Conshohocken

68. Trtnik G, Turk G, Kavčič F, Bosiljkov VB (2008) Possibilities of using the ultrasonic wave transmission method to estimate initial setting time of cement paste. Cem Concr Res 38:1336-1342. https://doi.org/10.1016/j.cemconres.2008. 08.003

69. Reinhardt HW, Grosse CU (2004) Continuous monitoring of setting and hardening of mortar and concrete. Constr Build Mater 18:145-154. https://doi.org/10.1016/j.conbuildmat. 2003.10.002

70. Zongjin Li, Lianzhen Xiao, Xiaosheng Wei (2007) Determination of concrete setting time using electrical resistivity measurement. J Mater Civ Eng 19:423-427. https://doi.org/ 10.1061/(ASCE)0899-1561(2007)19:5(423) 